\title{
Physical properties of a nickel-base alloy prepared by isostatic pressing and sintering of the powdered metal*
}

\author{
R. A. FUYS, JR, R. G. CRAIG and K. ASGAR University of \\ Michigan, School of Dentistry, Ann Arbor, Michigan
}

\section{Summary}

The physical and mechanical properties of samples of a nickel-base alloy fabricated by powder metallurgy were determined. The particle sizes of the powders used to make the samples varied from $-80 /+200$ mesh to -325 mesh. The compaction pressure varied from 138 to $414 \mathrm{MN} / \mathrm{m}^{2}$ and the sintering temperature varied from 1150 to $1250^{\circ} \mathrm{C}$. The shrinkage during processing, the porosity, tensile strength, yield strength, elongation, and elastic modulus were used to characterize the samples. The strength of the samples generally increased with decreasing particle size of the powder and increasing compaction pressure and sintering temperatures. The porosity and strength, therefore, could be varied over a wide range by controlling the various parameters. The properties of the samples prepared by powder metallurgy were compared with those of the cast alloy and compact bone. Conditions can be selected that will yield equivalent or better properties by powder metallurgy than by casting.

\section{Introduction}

Chromium-cobalt alloys, stainless steel, tantalum and titanium alloys have been employed in the dental and medical professions as prosthetic devices and surgical implants. Many appliances are custom-made using investment casting procedures while others are commercially available as cast or wrought performed products.

In the past few years significant advances have been made in the area of powder metallurgy with respect to manufacturing powders and methods of compaction. Parts with mechanical properties exceeding those of corresponding conventionally cast parts have been produced. In many instances, higher ductility and toughness can be achieved using a powder metallurgy process as opposed to a conventional casting process.

An advantage of the powder metallurgy process of frequent importance is that the porosity and density of the part can be controlled. Control of the pore structure is advantageous when the part is to be used as an implant where pores of particular size are necessary for the ingrowth of bone and soft tissue.

\footnotetext{
* Taken from a portion of a dissertation in partial fufilment of the requirements for the Ph.D. degree, University of Michigan, Horace H. Rackham School of Graduate Studies, 1971.

Correspondence: Dr Robert G. Craig, University of Michigan School of Dentistry, Department of Dental Materials, Ann Arbor, Michigan 48104, USA.
} 
The current casting alloys used as implants have modulus of elasticities about ten times greater than that of bone and the powder metallurgy process would allow fabrication of prosthetic parts with properties closer to those of bone than those prepared by casting techniques.

Isostatic pressing is the name used by Jackson (1967) when a powder is compacted by applying pressure simultaneously and equally in all directions in a tightly sealed flexible mould. The origin of the isostatic pressing technique appears to be an apparatus described by Madden (1912). The pressure can be transmitted by liquids, gases, rubbers, plastics and glasses with oil or water being used most frequently.

Van Buren \& Hirsch (1960) showed that a given powder, processed under the same conditions, will possess better mechanical properties when isostatically pressed as opposed to die-pressed. They found the greatest improvement in properties in the ductility of the sintered part. They observed greater uniformity of density of parts prepared by isotatic pressing which resulted in a more uniform shrinkage during sintering. They also showed that hard powders could be isostatically pressed with reasonable ease but these same powders were difficult if not impossible to press by die-pressing.

Weisert \& Schwarzkopf (1971) listed the following advantages of isostatic pressing: (1) the size of the part is limited only by the size of the pressure vessel, (2) re-entrant, undercut and long thin-walled shapes can be pressed, (3) no limit exists on the number of changes in the thickness of the sections or the length to diameter ratios, and (4) low cost of tooling. Marshal (1968) showed that the absence of friction at the wall of the mould in isostatic pressing resulted in the elimination of the use of a lubricant with the powder. It was established by Hirschhorn \& Reynolds (1969) that movement and deformation of powder particles occur to a greater extent and in a much more uniform manner for isostatic compacts than those prepared by other compaction techniques.

The purpose of this investigation was to isostatically compact a commercially available nickel-base partial denture casting alloy over a range of temperatures, and to determine the properties of the pressed and sintered samples. The properties to be measured included density, dimensional change on pressing and sintering, tensile strength, yield strength, modulus of elasticity and elongation. The effect of porosity on these properties also will be demonstrated.

\section{Materials and methods}

Powder characterization. Commercially available Ticonium 100*, a partial denture casting alloy, was used but any one of a number of similar alloys could have been selected. The alloy was converted to powder by water-atomization $\dagger$ which resulted in irregularly-shaped powder particles with an oxygen content of $0.068 \%$.

The powder was separated into samples with different mesh sizes using standard sieves and the apparent density determined in accordance with MPIF Standard 4-45 and the values are listed in Table 1 . The values reported are means of three determinations. The surface of the particles was highly irregular as shown in the scanning electron micrographs at 500-10,000 magnification (Fig. 1).

Isostatic pressing technique-Urethane bags with $9.5 \mathrm{~mm}$ inside diameter and $63.5 \mathrm{~mm}$ length were designed with $0.8 \mathrm{~mm}$ thick walls. The bags were made by

* Ticonium Division, CMP Industries, Albany, N.Y.

$\dagger$ Federal Mogul Division, Federal Mogul Corp., Ann Arbor, Michigan. 
Table 1. Apparent density of the nickel-base powders of different sieve sizes

\begin{tabular}{rrr}
\hline Sieve size & $\begin{array}{r}\text { Apparent density } \\
\left(\mathrm{g} / \mathrm{cm}^{3}\right)\end{array}$ & $\begin{array}{r}\text { Weight used } \\
9 \cdot 5 \times 63 \cdot 5 \mathrm{~mm} \mathrm{bag}(\mathrm{g})\end{array}$ \\
\hline$-80 /+200$ & $1 \cdot 92$ & $12 \cdot 0$ \\
$-80 /+325$ & $2 \cdot 03$ & $11 \cdot 5$ \\
-80 & $2 \cdot 23$ & $13 \cdot 5$ \\
-200 & $2 \cdot 28$ & $14 \cdot 5$ \\
-325 & $2 \cdot 49$ & $15 \cdot 5$ \\
\hline
\end{tabular}
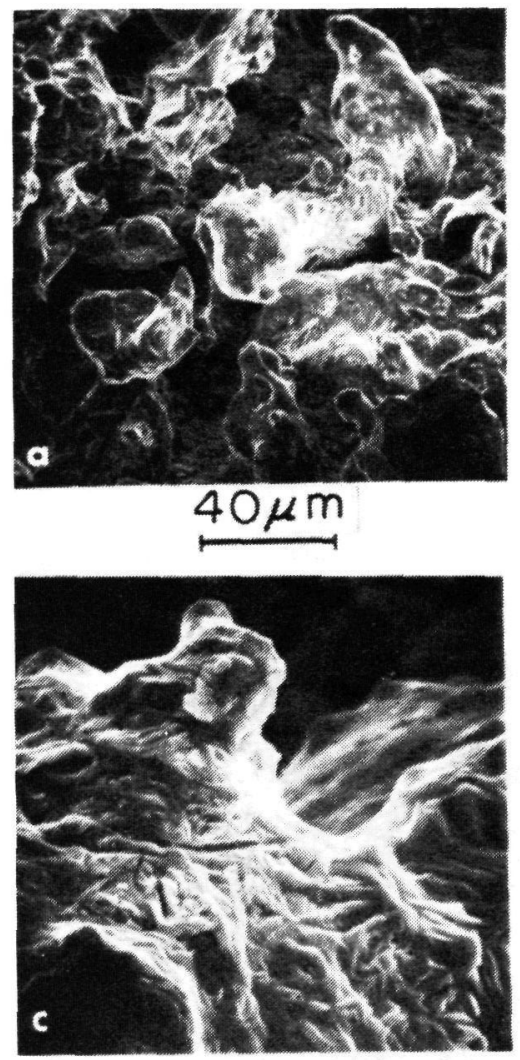

$4 \mu \mathrm{m}$

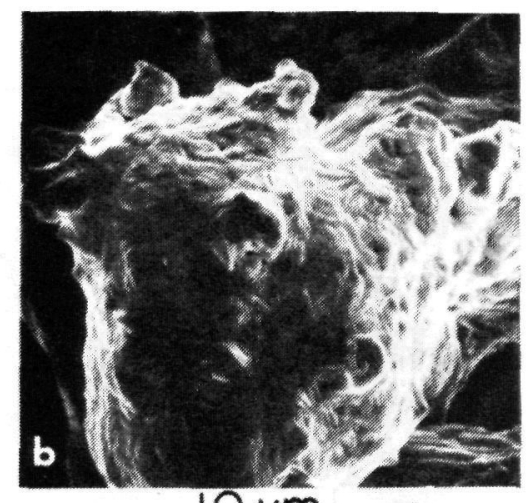

$10 \mu \mathrm{m}$

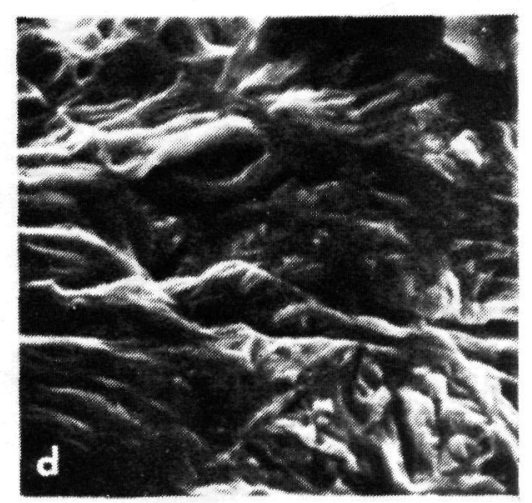

$1 \mu \mathrm{m}$

Fig. 1. Scanning electron micrographs of Ticonium 100, - 200 mesh.

mixing the two components for the urethane* at room temperature, degassing and then casting the bags by pouring the mix into appropriate brass dies. Examples of the urethane bags and plugs are shown in Fig. 2. Neoprene, natural rubber tubing, silicone rubber and vinyl plastisols were investigated but the urethane bag was superior.

Since the apparent density varied with the mesh size a predetermined weight of powder was used for a given mesh size and the values are given in Table 1. After the bag was filled, it was sealed with the plug and taped. Compaction was done in a pressure vessel $\dagger$ using a kerosene-oil mixture at 138,276 or $414 \mathrm{MN} / \mathrm{m}^{2}$ for $5 \mathrm{~min}$. The pressurization rate was $17 \cdot 2$ to $20 \cdot 7 \mathrm{MN} / \mathrm{m}^{2} / \mathrm{min}$, and therefore 20-25 min were

* Hardman Inc., 600 Courtlondt, Belleville, N.J.07109.

$\dagger\left(414 \mathrm{MN} / \mathrm{m}^{2}\right)$ 60,000 psi AMINCO Porosimeter, American Instrument Co., Silver Spring, Md. 


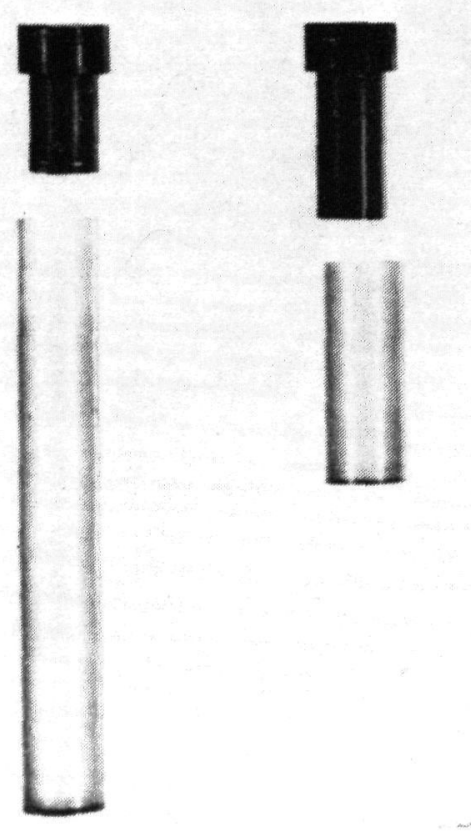

Fig. 2. Flexible polyurethane bags and plugs for the compaction of metal powders.

required to attain a pressure of $414 \mathrm{MN} / \mathrm{m}^{2}$. Satisfactory compacts were obtained except for -325 and -200 mesh powders at $138 \mathrm{MN} / \mathrm{m}^{2}$ and for -325 mesh powder at $276 \mathrm{MN} / \mathrm{m}^{2}$. The pressure was released and the pressed compacts removed from the bags.

Sintering. Sintering was done in a furnace under vacuum. The vacuum system consisted of a mechanical pump, an oil diffusion pump and a cold trap. A glow-bar tube furnace*, with a mullite combustion tube and ceramic boats $\dagger$, was used to heat the samples in vacuum. The system was evacuated to $10^{-6}$ Torr and then the furnace was heated to the desired temperature. Trials showed the incipient melting occurred at $1300^{\circ} \mathrm{C}$ but none took place at $1250^{\circ} \mathrm{C}$. Sintering temperatures of 1150,1200 and $1250^{\circ} \mathrm{C}$ were selected to study the effect of temperature on properties. The samples were maintained at the desired sintering temperature for $2 \mathrm{~h}$ and the furnace was allowed to cool under vacuum and the samples removed.

Determination of properties. The percent linear change in dimensions was determined using a micrometer. The apparent density, defined as the weight per volume, was used to calculate the present theoretical density by dividing the apparent density by the true density $\times 100$.

The tensile strength, $0 \cdot 1 \%$ offset yield strength, modulus of elasticity and percent elongation were determined on tensile samples prepared by centreless grinding of the sintered compacts. The tensile samples were ground to a diameter of $3 \mathrm{~mm}$ with a gauge length of $10 \mathrm{~mm}$. The mechanical properties were determined using an Instron $\ddagger$ testing machine at a cross-head speed of $0.05 \mathrm{~cm} / \mathrm{min}$ and a $10 \mathrm{~mm}$ strain gauge extensometer. Values reported are means of duplicate tests.

The porosity of the samples was determined by mercury intrusion porosimetry as described by Rootare (1970). The method consists of measuring simultaneously the

* Lindberg Hevi-Duty, Div., Sola Basic Industries, 304 Hart St., Watertown, Wisc.

$\dagger$ Lecotherm, Leco Laboratory Equipment Corp., St Joseph, Mi. 49085.

$\ddagger$ Instron Corporation, 2500 Washington St., Canton, Mass. 02021. 
pressure and volume of mercury that penetrates a sample up to that pressure. The 60,000 psi porosimeter used for compacting the powders was used to determine the porosity.

\section{Results}

The percent change in length and diameter during the pressing of the various powders at 138, 276 and $414 \mathrm{MN} / \mathrm{m}^{2}$ is shown in Fig. 3. The percent change in diameter was consistently less than the per cent change in length for comparable samples, the largest difference being about $2 \%$. As expected, higher compaction pressures resulted in greater dimensional change. Finer particle size powders experienced less dimensional change during compaction than larger sizes and the $-80 /+200$ and the $-80 /+325$ sizes, in which the very fine particles were removed, had the largest dimensional change.

The percent shrinkage in length of the compacts prepared under pressures of 138 , 276 and $414 \mathrm{MN} / \mathrm{m}^{2}$ and at temperatures of 1150,1200 and $1250^{\circ} \mathrm{C}$ is presented in Fig. 4. Increasing the sintering temperature from 1150 to $1250^{\circ} \mathrm{C}$ increased the shrinkage from about 2 to $8-10 \%$ for samples compacted at 138 and $276 \mathrm{MN} / \mathrm{m}^{2}$ and from about 2 to $6-8 \%$ for samples compacted at $414 \mathrm{MN} / \mathrm{m}^{2}$. In general, for a given condition greater shrinkage was observed the smaller the particle size of the powder. The percent shrinkage in the diameter corresponded to those in length except they were slightly lower as observed previously in Fig. 3.

The percent of the theoretical density and apparent density of the compacted and sintered powders are given in Fig. 5. A maximum value of $97 \%$ for the percent theoretical density was attained for the -325 mesh powder pressed at $414 \mathrm{MN} / \mathrm{m}^{2}$ and sintered at $1250{ }^{\circ} \mathrm{C}$. The minimum value of $56 \%$ was obtained for the theoretical density when the $-80 /+200$ mesh powder was compacted at $138 \mathrm{MN} / \mathrm{m}^{2}$ and sintered at $1150{ }^{\circ} \mathrm{C}$. Intermediate values of the percent theoretical density were obtained by using intermediate compaction pressure and sintering temperatures.

The tensile strengths of the various sintered compacts are illustrated in Fig. 6. The

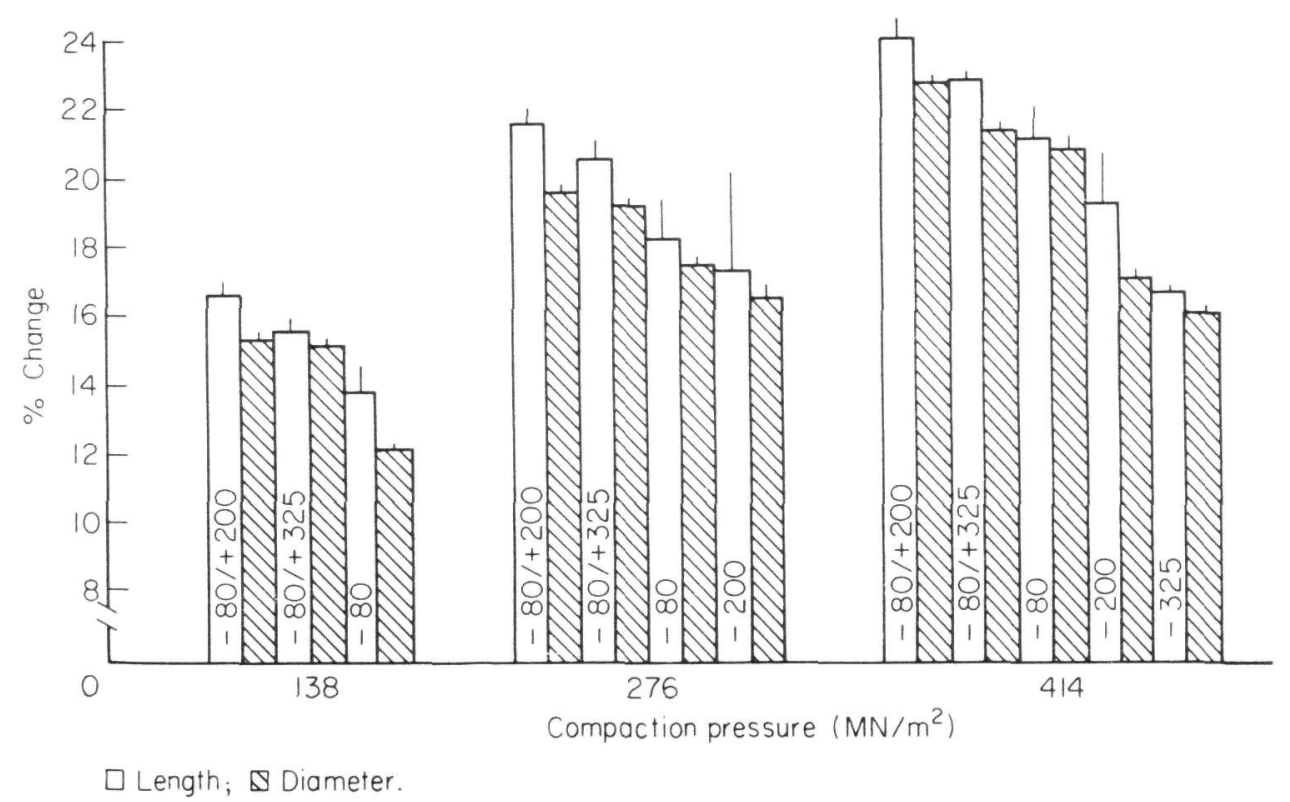

Fig. 3. Dimensional change on compaction of Ticonium 100 powder in $9 \cdot 5 \times 63 \cdot 5 \mathrm{~mm}$ polyurethane bags. (Average of 6 values; the vertical lines at the top of the bars indicate the standard deviation.) 


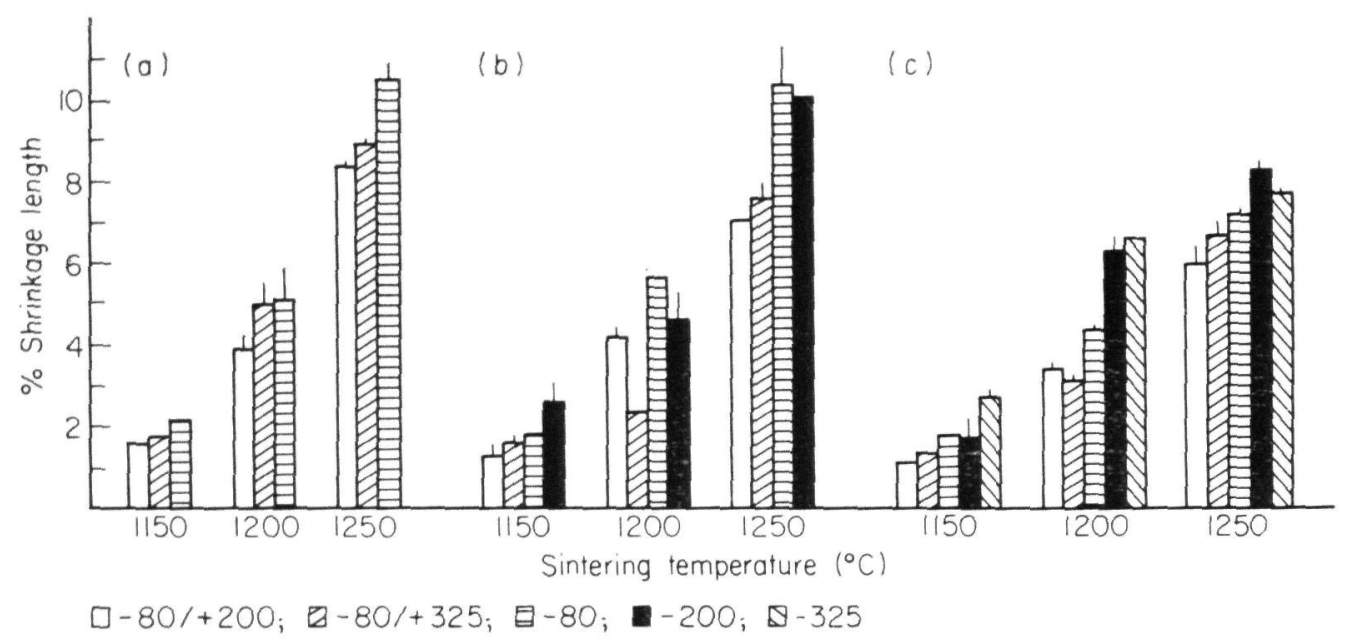

Fig. 4. Percent shrinkage in length vs sintering temperature for Ticonium 100 powders at three compaction pressures using the $63.5 \mathrm{~mm}$ long polyurethane bags. (Average of 2 samples with the mean deviation). Compaction pressure: a, $138 \mathrm{MN} / \mathrm{m}^{2} ; \mathrm{b}, 276 \mathrm{MN} / \mathrm{m}^{2} ; \mathrm{c}, 414 \mathrm{MN} / \mathrm{m}^{2}$.

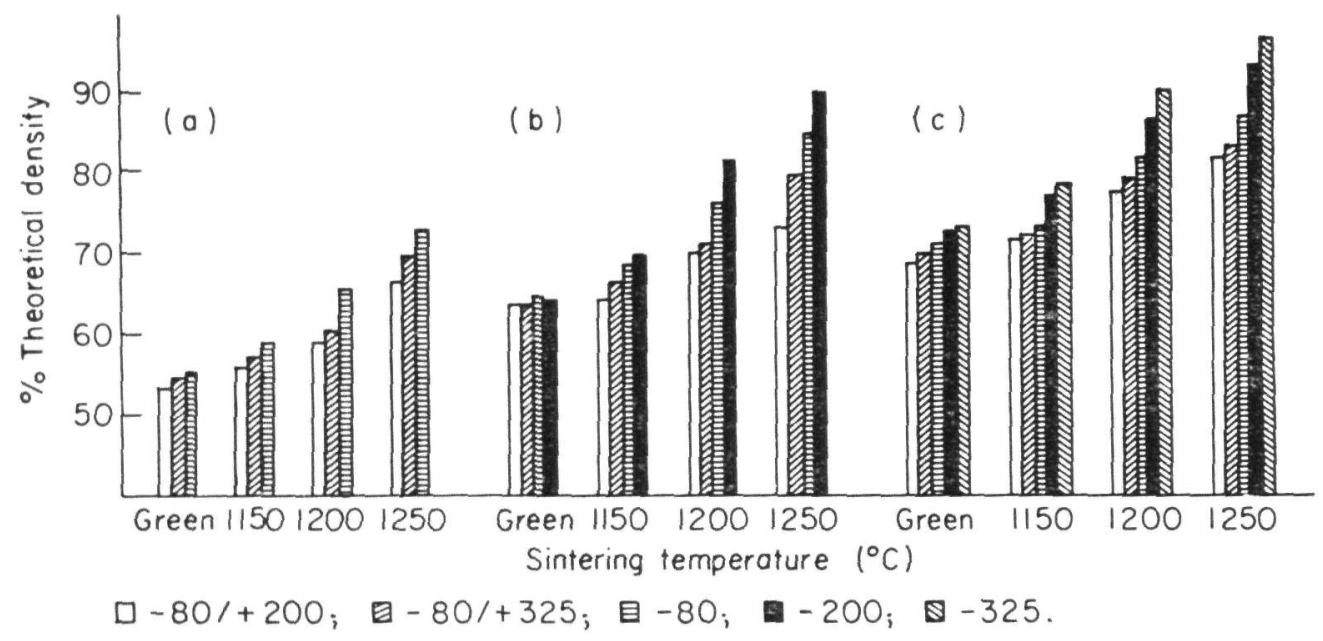

Fig. 5. Percent of the theoretical density and apparent density vs sintering temperature and compaction pressures for Ticonium 100 powders. Compaction pressure: a, $138 \mathrm{MN} / \mathrm{m}^{2} ; \mathrm{b}, 276 \mathrm{MN} / \mathrm{m}^{2} ; \mathrm{c}, 414$ $\mathrm{MN} / \mathrm{m}^{2}$.

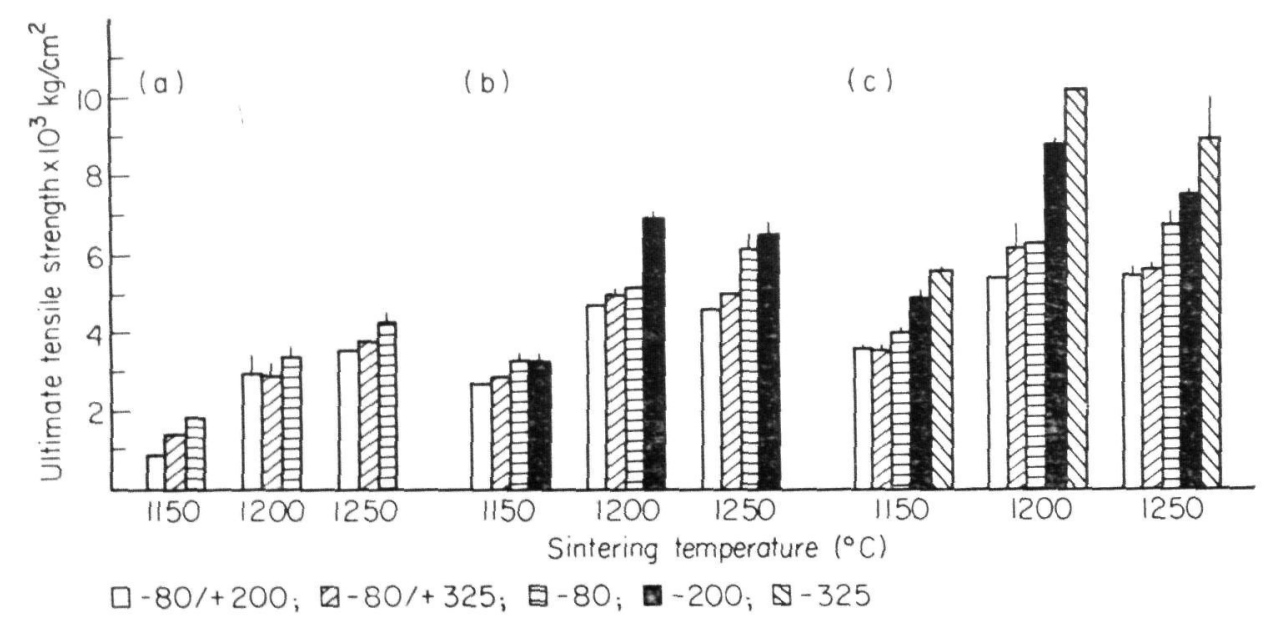

Fig. 6. Tensile strengths of sintered compacts as a function of the compaction pressure and sintering temperature. Compaction pressure: a, $138 \mathrm{MN} / \mathrm{m}^{2} ; \mathrm{b}, 276 \mathrm{MN} / \mathrm{m}^{2} ; \mathrm{c}, 414 \mathrm{MN} / \mathrm{m}^{2}$. 
tensile strength ranged from a low of $900 \mathrm{~kg} / \mathrm{cm}^{2}\left(89 \cdot 9 \mathrm{MN} / \mathrm{m}^{2}\right)$ for the $-80 /+200$ mesh powder compacted at $138 \mathrm{MN} / \mathrm{m}^{2}$ and sintered at $1150^{\circ} \mathrm{C}$ to a high of $10,200 \mathrm{~kg} /$ $\mathrm{cm}^{2}\left(1000 \mathrm{MN} / \mathrm{m}^{2}\right)$ for the -325 mesh powder compacted at $414 \mathrm{MN} / \mathrm{m}^{2}$ and sintered at $1200^{\circ} \mathrm{C}$. The following trends were observed: (1) the tensile strength increased with decreasing particle size and increasing compaction pressure; (2) maximum tensile strengths were attained for compacts prepared at $138 \mathrm{MN} / \mathrm{m}^{2}$ at a sintering temperature of $1250^{\circ} \mathrm{C}$; and (3) for compacts prepared at 276 and $414 \mathrm{MN} / \mathrm{m}^{2}$ maximum tensile strengths were obtained at the sintering temperature at $1200^{\circ} \mathrm{C}$ except for the -80 mesh powder which had maximum values when sintered at $1250^{\circ} \mathrm{C}$.

The $0.1 \%$ offset yield strength data are shown in Fig. 7. The values ranged from $700 \mathrm{~kg} / \mathrm{cm}^{2}\left(66 \cdot 2 \mathrm{MN} / \mathrm{m}^{2}\right)$ for $-80 /+200$ mesh powder compacted at $138 \mathrm{MN} / \mathrm{m}^{2}$

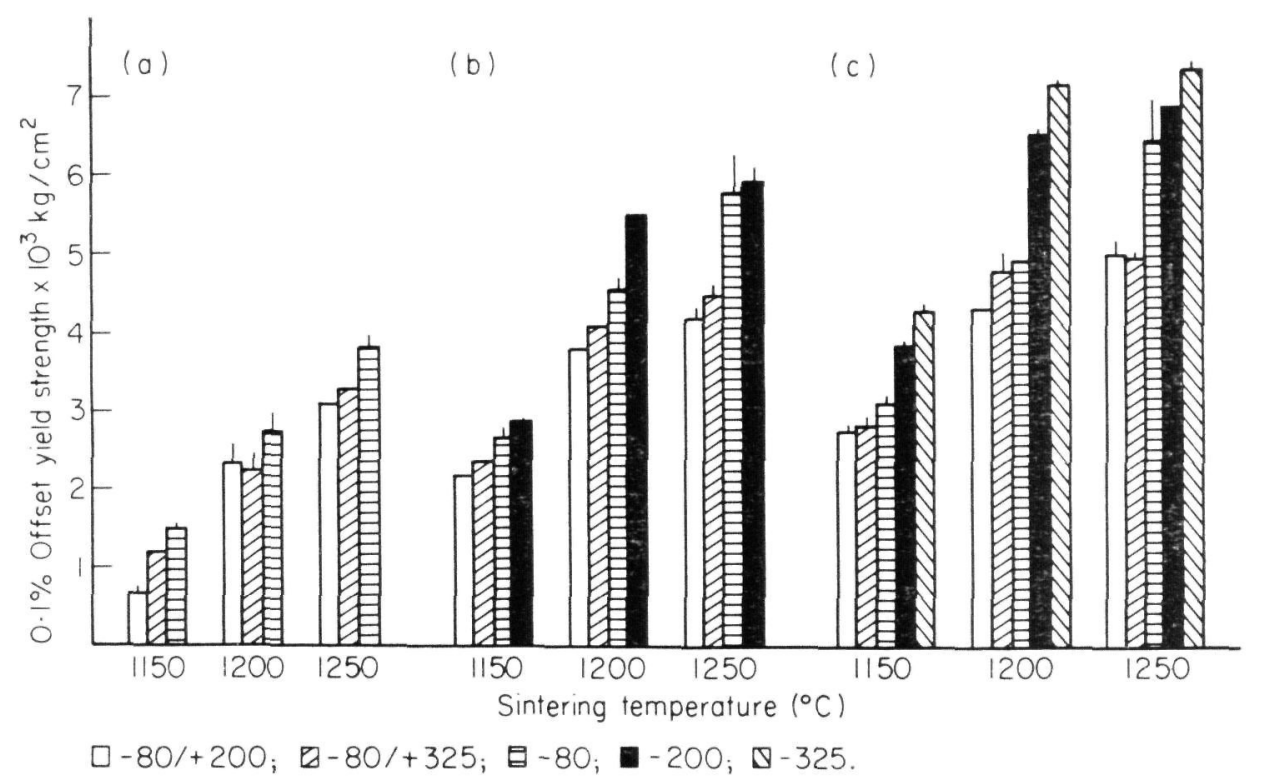

Fig. 7. Yield strengths $(0 \cdot 1 \%$ offset $)$ of sintered compacts vs the compaction pressure and sintering temperature. Compaction pressure: a, $138 \mathrm{MN} / \mathrm{m}^{2} ; \mathrm{b}, 276 \mathrm{MN} / \mathrm{m}^{2} ; \mathrm{c}, 414 \mathrm{MN} / \mathrm{m}^{2}$.

and sintered at $1150^{\circ} \mathrm{C}$ to $7200 \mathrm{~kg} / \mathrm{cm}^{2}\left(745 \mathrm{MN} / \mathrm{m}^{2}\right)$ for -325 mesh powder compacted at $414 \mathrm{MN} / \mathrm{m}^{2}$ and sintered at $1250^{\circ} \mathrm{C}$. In general the yield strength increased with decreasing particle size of the powder, and increasing compaction pressure and sintering temperature.

The percent elongation for the various samples is presented in Fig. 8 as a function of density of the sintered specimens. The elongation of specimens with densities less than $6 \mathrm{~g} / \mathrm{cm}^{3}$ was less than $4 \%$. The elongation increased rapidly at higher density with the samples ( -325 mesh) sintered at $1200^{\circ} \mathrm{C}$, compacted at $414 \mathrm{MN} / \mathrm{m}^{2}$, and a density of about $7 \mathrm{~g} / \mathrm{cm}^{3}$, having an elongation of approximately $12 \%$; the theoretical density is $8.0 \mathrm{~g} / \mathrm{cm}^{3}$. The samples ( $-325 \mathrm{mesh}$ ) compacted at $414 \mathrm{MN} / \mathrm{m}^{2}$ and sintered at $1250^{\circ} \mathrm{C}$ also had elongations of about $12 \%$ but had higher densities of about $7 \cdot 8 \mathrm{~g} / \mathrm{cm}^{3}$.

The relative modulus of elasticity, $\mathrm{E} / \mathrm{E}_{0}$, where $\mathrm{E}$ is the modulus of a sample and $E_{0}$ is the modulus of a non-porous sample of $1 \cdot 8 \times 10^{6} \mathrm{~kg} / \mathrm{cm}^{2}\left(207,000 \mathrm{MN} / \mathrm{m}^{2}\right)$, is plotted as a function of the fractional porosity in Fig. 9. The fractional porosity is defined as one minus the density of the porous sample divided by density of pore-free samples or as one minus the present theoretical density divided by 100 . The relative 


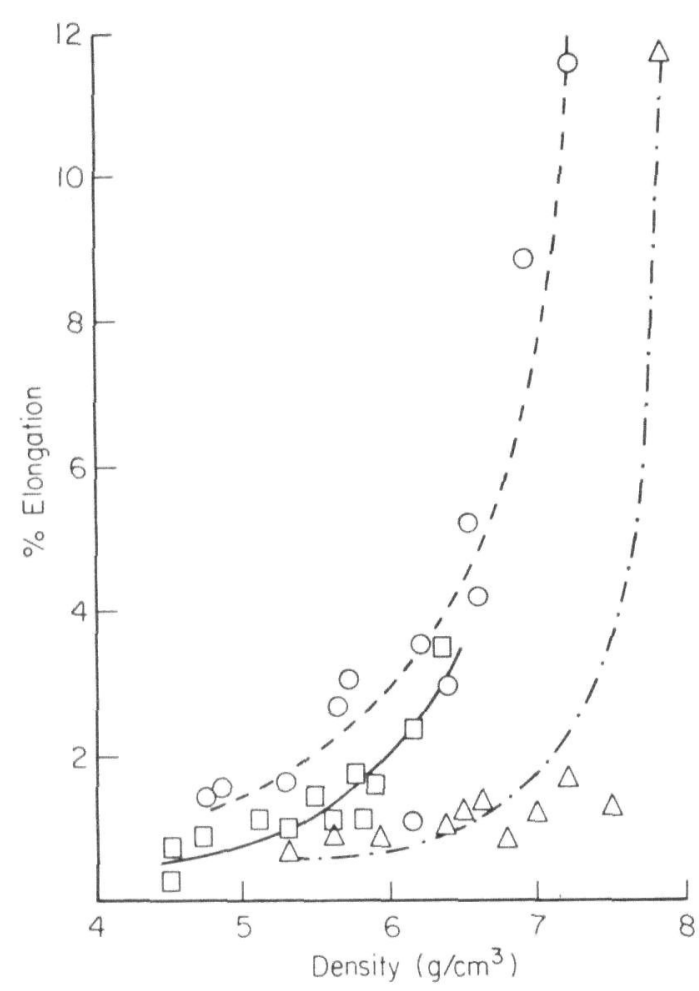

$\square, 1150^{\circ} \mathrm{C} ; 0,1200^{\circ} \mathrm{C} ; \triangle, 1250^{\circ} \mathrm{C}$.

Fig. 8. Percent elongation as a function of density for sintered specimens.

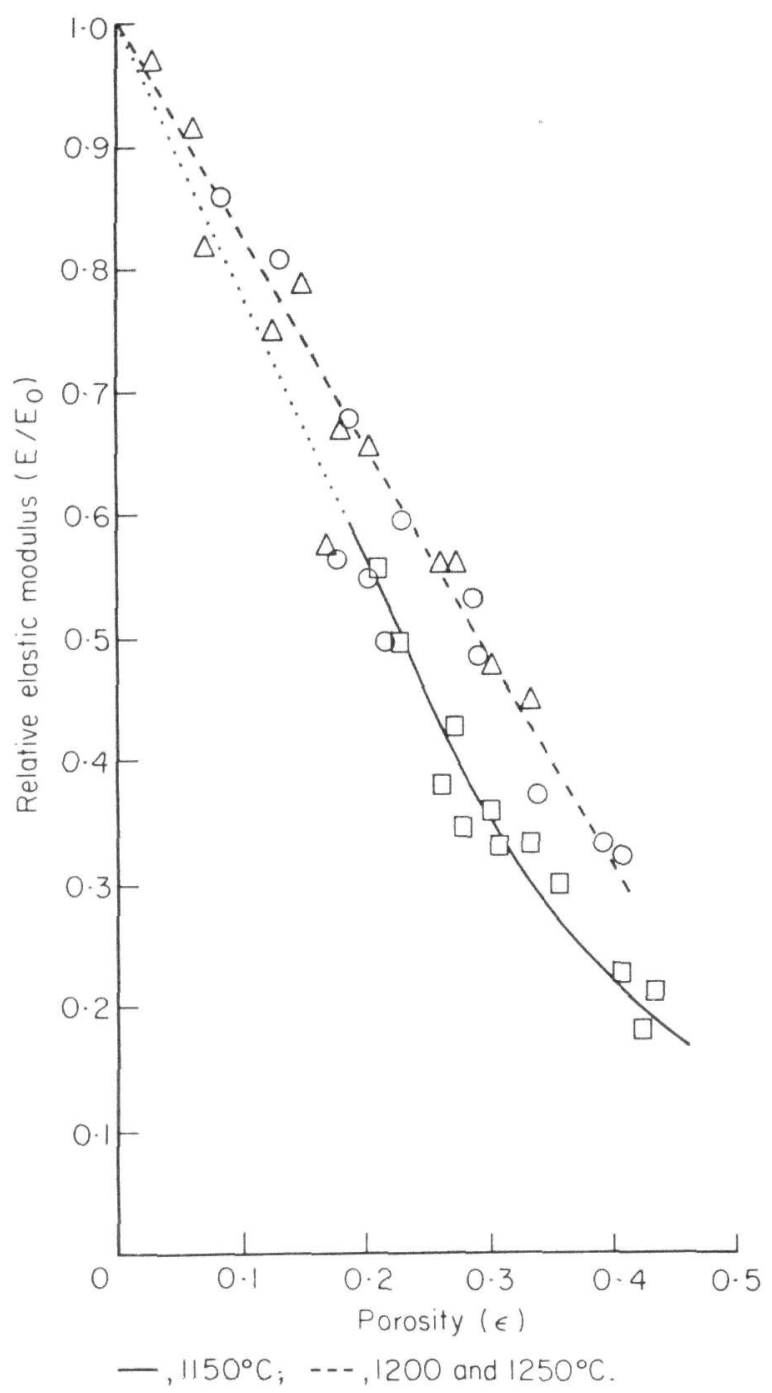

Fig. 9. Relationship between relative modulus of elasticity, $\mathrm{E} / \mathrm{E}_{0}$, of sintered compacts and fractional porosity $(\epsilon)$.

modulus and fractional porosity had a linear relationship for fractional porosities less than 0.3 for all samples and was linear up to fractional porosity of 0.4 for sintering temperatures from 1200 to $1250^{\circ} \mathrm{C}$.

\section{Discussion}

The following generalizations can be made about the properties of compacts and sintered compacts and the effect of compaction pressure and sintering temperatures. Increasing the compaction pressure and particle size of the powder increased the dimensional change during compaction of the powders. Also, the percent change in diameter of cylindrical specimens was consistently greater than the length during compaction for comparable conditions. The changes were readily repeatable and thus the dimensions of the compacts could be controlled by using oversized polyurethane bags.

The percent of the theoretical density increased with decreases in particle size of the powders and increases in the compaction pressure and sintering temperature. Thus the percent theoretical density, which is related to the porosity, could be varied as desired from 57 to $97 \%$ by the appropriate selection of parameters. 
The tensile and yield strengths generally increased with decreasing particle size and increasing compaction pressure and sintering temperature. In a few instances values for samples sintered at $1200^{\circ} \mathrm{C}$ were equal or slightly higher than comparable samples sintered at $1250^{\circ} \mathrm{C}$. The percent elongation also generally increased with decreasing particle size and increasing compaction pressure and sintering temperature although the increases were small with the exception of the finest powders compacted at the highest pressures and sintered at the highest temperatures. The elastic modulus, however, showed the same general progression of increases as did the tensile and yield strengths for the various parameters.

Mechanical properties of selected samples prepared by powder metallurgy are compared with the properties of the cast metal and compact bone in Table 2 . It is

Table 2. Properties of powder metallurgy samples, cast alloy and compact bone

\begin{tabular}{|c|c|c|c|c|c|c|}
\hline Sample & $\begin{array}{r}\text { Tensile } \\
\text { strength } \\
\left(\mathrm{kg} / \mathrm{cm}^{2}\right)\end{array}$ & $\begin{array}{r}\text { Yield strength } \\
0 \cdot 1 \% \text { Offset } \\
\left(\mathrm{kg} / \mathrm{cm}^{2}\right)\end{array}$ & $\begin{array}{r}\text { Modulus of } \\
\text { elasticity } \\
\left(\mathrm{kg} / \mathrm{cm}^{2} \times 10^{6}\right)\end{array}$ & $\begin{array}{r}\text { Elongation } \\
(\%)\end{array}$ & $\begin{array}{r}\text { Interconnected } \\
\text { porosity } \\
\left(\mathrm{cm}^{3} / \mathrm{g}\right)\end{array}$ & $\begin{array}{r}\% \text { Theoretical } \\
\text { density }\end{array}$ \\
\hline $1 *$ & 900 & 700 & $0 \cdot 44$ & $0 \cdot 4$ & 0.09 & 56 \\
\hline $2 *$ & 3500 & 3100 & 0.95 & $0 \cdot 8$ & $0 \cdot 06$ & 67 \\
\hline $3 *$ & 10200 & 7200 & $1 \cdot 80$ & $11 \cdot 6$ & 0.005 & 96 \\
\hline $\begin{array}{l}\text { Cast } \\
\text { alloy } \dagger\end{array}$ & 10300 & 8080 & $1 \cdot 90$ & $7 \cdot 3$ & - & 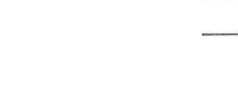 \\
\hline $\begin{array}{c}\text { Compact } \\
\text { bone } \div\end{array}$ & 1400 & - & $0 \cdot 18$ & $1 \cdot 5$ & - & - \\
\hline
\end{tabular}

* Sample $1-80 /+200$ mesh, $138 \mathrm{MN} / \mathrm{m}^{2}, 1150^{\circ} \mathrm{C} / 2 \mathrm{~h}$; Sample $2-80 /+200$ mesh, $138 \mathrm{MN} / \mathrm{m}^{2}$, $1250^{\circ} \mathrm{C} / 2 \mathrm{~h}$; Sample $3-325$ mesh, $414 \mathrm{MN} / \mathrm{m}^{2}, 1200^{\circ} \mathrm{C} / 2 \mathrm{~h}$.

$\dagger$ Manufacturers data sheet, May 1965, Tic, Vol. XXIV, No. 5.

\$ Average of femur, tibia, fibula, humerus, radius and ulna of individuals 20-39 years of age (Evans, 1970).

apparent that a wide range of mechanical properties are possible in samples prepared by powder metallurgy that have about a 20 -fold difference in interconnected porosity and a $40 \%$ difference in theoretical density. Even wider variations are possible by further varying the parameters studied. The mechanical properties of sample 3 are equal to or better than the comparable cast metal. The higher elongation of $11 \cdot 6 \%$ for sample 3 compared with $7 \cdot 3 \%$ for the cast alloy, in spite of it having only $96 \%$ of the theoretical density, may be explained on the basis of the more homogeneous and smaller $(\sim 100 \mu \mathrm{m})$ grain size of the samples prepared by powder metallurgy compared to the cast alloy where a typical grain size would be $>500 \mu \mathrm{m}$.

The properties of compact bone illustrate that the modulus is even lower than that for powder metallurgy for sample 1 and that the elongation of bone is more than that for sample 2. It appears that in order to match these properties of bone a powder metallurgy part would need to have greater porosity than sample 1 and then be infiltrated with a polymer.

In summary, it is possible by varying the particle size of the powders, the compaction pressure, and sintering conditions to control the mechanical properties and porosity of a nickel-base alloy to more nearly match those of compact bone. Increased elongation was possible with parts fabricated by powder metallurgy compared with cast parts. 


\section{Acknowledgment}

This study was supported in part by Training Grant DE-00181 from the National Institutes of Health, Bethesda, Md. 20014.

\section{References}

Evans, F.G., ed. (1970) Strength of Biological Materials, pp. 19-21. Williams and Wilkins, Baltimore.

HiRSCHHORN, J.S. \& ReYNOLDS, J.T. (1969) Powder metallurgy fabrication of cobalt alloy surgical implant materials. In: Research in Dental and Medical Materials (Ed. by E. Korostoff). Plenum Press, New York.

JACKSON, H.C. (1967) Isostatic pressing of powdered materials. In: Perspectives in Powder Metallurgy (Ed. by H. Hausner), p. 13. Plenum Press, New York.

Madden, H.D. (March 28, 1912) Process of preparing billets of refractory materials. U.S. Patent 1,081,618 (Westinghouse Lamp Co.).

Marshal, P.R. (1968) The production of powder metallurgy parts. Metals Review, 123, 53.

Rootare, H,M. (1970) A review of mercury porosimetry. In: Perspectives in Powder Metallurgy (Ed. by H.H. Hausner, K.H. Roll and P.K. Johnson), p. 225. Plenum Press, New York.

Van Buren, C.E. \& Hirsch, H.H. (1960) Hydrostatic pressing of powders. General Electric Research Laboratory Report No. 60-RL-2538M, New York.

Weisert, E.D. \& Schwarzkopf, P. (1971) Isostatic pressing: a three dimensional process. Metal Progress, 99, 71.

Manuscript accepted 28 April 1975 
This document is a scanned copy of a printed document. No warranty is given about the accuracy of the copy. Users should refer to the original published version of the material. 